\title{
Middle School Curricular Materials on Grand Challenges for Engineering: Impact on Efficacy and Expectancy Beliefs
}

\section{Dr. Kimberly A.S. Howard, Boston University}

Dr. Kimberly Howard is an Associate Professor in Counseling Psychology in the Boston University School of Education.

\author{
Mr. Jacob William Diestelmann, University of Wisconsin - Madison \\ Tsu-Lun Huang \\ Lauren E Aneskavich \\ Mr. Kevin Cheng \\ Benjamin Bryan Crary, University of Wisconsin - Madison \\ Jean DeMerit, UW-Madison \\ Tam Mayeshiba, University of Wisconsin-Madison
}

Tam Mayeshiba is a National Science Foundation Graduate Research Fellow/graduate student in the Materials Science Program at the University of Wisconsin-Madison, studying fast oxygen conduction for energy technologies using high-throughput ab-initio computation.

\section{Prof. Amy K Schiebel, Edgewood College}

Amy Schiebel is an Associate Professor in the Natural Sciences at Edgewood College where she works as the Director of their unique K-16 Science Program and Directs the Office of Science Outreach since 2002. She holds a B.S. and M.S. in Geology and an M.A.T. and Ph.D. in Science Education, the later three degrees from the University of Iowa. She has spent the past 25 years working in curriculum design and development, teacher preparation, teacher professional development, and undergraduate science education as well as designing informal science environments and experiences. Prior to joining the Edgewood faculty she taught Junior High Science and served as a Visiting Professor at the University of Iowa.

Prof. Susan C. Hagness, University of Wisconsin, Madison

Dr. Steven M. Cramer, University of Wisconsin, Madison

Prof. Amy E. Wendt, University of Wisconsin - Madison 


\title{
Middle School Curricular Materials on Grand Challenges for Engineering: Impact on Efficacy and Expectancy Beliefs (Research to Practice)
}

\author{
Strand: Other
}

\section{Introduction}

Efforts to increase STEM career interests have often focused on high school youth. However, middle school is a critical juncture during which many students begin to seriously consider career options. Attitudes about self and work developed during this period form the foundational belief system from which students set career goals and choose high school courses and activities $^{1}$. The method by which STEM activities are presented during middle school can have a profound impact on students' motivation and interest to pursue careers in STEM related fields ${ }^{2,3}$.

Pre-college STEM education efforts have not been evenly distributed across the four subjects represented by the STEM acronym. While math and science are core middle and high school subject areas, engineering education has been more slowly adopted in formal education settings. The impetus for providing youth with learning experiences in engineering has been two-fold: to support achievement in math and science and to broaden post-secondary engineering involvement ${ }^{4}$. Encouraging the development of engineering career interests is critical to accomplishing this second goal and can also serve to motivate student attention toward building a foundation in math and science.

This paper presents a study of a pilot implementation of an engineering curriculum that focuses on humanitarian applications while reinforcing math and science concepts. The curriculum was piloted in middle school math and science classes in Wisconsin. The purpose of this study is to evaluate whether students' self-reported social cognitive beliefs towards math and science differed by membership in either the pilot curriculum or a comparison group. This study is part of a larger endeavor to understand the impact that engaging with the engineering-based curriculum has on student beliefs about, exploration of, and interest in STEM-related occupations generally, and engineering-related occupations specifically. This paper will focus on social cognitive outcomes only, based on surveys completed by participating and comparison student groups before and after instruction using the pilot curriculum during the 2012-13 academic year.

\section{Theoretical \& Empirical Foundations}

Emerging from the application of Bandura's social cognitive theory ${ }^{5,6}$ to career development ${ }^{7}$, Social Cognitive Career Theory (SCCT) ${ }^{8}$ describes the role of beliefs in the development of career interests. According to SCCT, STEM career interests are supported by one's sense of confidence and performance expectations. Students who believe they have the requisite skills to succeed in STEM-related tasks and believe that spending time in such pursuits is meaningful are more likely to develop STEM career interests. Students develop these social cognitive beliefs through interaction with learning environments that nurture skills and these beliefs. 
According to SCCT, the learning experiences a student has are influenced by a variety of contextual influences including person characteristics such as gender, race/ethnicity, and disability/health status, as well as background contextual affordances such as socioeconomic status, social support, societal barriers, and location of residence. Learning experiences shape one's sense of self-efficacy and outcome expectations through the "sources of efficacy beliefs" described by Bandura, ${ }^{5,6}$, including mastery experiences, vicarious experiences, verbal persuasion, and anxiety management. The combination of self-efficacy beliefs and outcome expectations influences the direction of one's career interests, in that one is likely to be interested in careers for which one feels a minimum level of task-related competence and careers that are perceived to help one attain valued outcomes ${ }^{7,8}$.

The strength of occupational self-efficacy beliefs in contributing to women's career direction was established in a seminal study by Betz and Hackett ${ }^{7}$. Betz and Hackett found that women who were confident in their ability to complete math and science related tasks were more likely to be interested in math and science careers. This line of inquiry was further extended, finding that self-efficacy and outcomes expectations in math and science were predictive of an individual's interest in pursuing math and science occupations, even after controlling for an individual's ability in these areas ${ }^{9}$. Additional testing of the SCCT model with diverse middle school youth found that math/science self-efficacy predicted math/science outcome expectations, which in turn made unique and significant contributions to both math/science career interests and intentions to pursue math/science courses in high school ${ }^{10}$. Interventions designed to challenge engineering stereotypes and provide modeling experiences for youth increased the self-efficacy beliefs and interests in engineering of both male and female middle school students ${ }^{11}$. Further, $8^{\text {th }}$ grade self-efficacy beliefs for math-related tasks have been found to be predictive of engineering career interests in young adulthood ${ }^{12}$. SCCT variables, then, would be an important area of focus for programs endeavoring to broaden interest and participation in a particular area of study, such as engineering. Furthermore, learning activities that highlight the central role of math and science concepts in humanitarian engineering outcomes may impact student interest in math and science.

\section{Grand Challenges for Engineering Curriculum}

Using the National Academy of Engineering's Grand Challenges for Engineering ${ }^{13}$ as inspiration, an interdisciplinary team of engineers and science educators has developed a set of engineering-based math and science curriculum modules. This effort, titled Society's Grand Challenges for Engineering as a Context for Middle School STEM Instruction, is a research project initiated at UW-Madison in 2010 with support from the NSF ITEST program, with the objective of investigating the impact of instruction of math and science from the perspective of socially motivated engineering. The pilot modules are designed to serve as a model for the integration of engineering into science and math curricula in a way that accurately portrays both the distinct features of the disciplines and their interdependence. The message conveyed to students through these modules is that STEM careers are a means to making a difference in the world. Each module emphasizes engineering solutions to a distinct societal need through a realistic fictional scenario. Students participate through role play as engineers, experiencing the engineering design process while learning underlying math and science concepts. 
Our emphasis on altruistic engineering projects was motivated by the NAE Extraordinary Women Engineers Project ${ }^{14}$, which identified messaging as an important factor in the low representation of women in undergraduate engineering programs. An extensive survey of high school students systematically concludes that messaging about engineering, with an emphasis on "math and science skills" and the notion of a "challenge," is not aligned with key motivators for girls. Rather, results showed that messages that focus on features of the engineering profession not widely emphasized, such as "making a difference in the world" and "creativity," hold much stronger appeal. The survey also found that both male and female students rank engineering as the least desirable among professions listed, behind teacher, doctor, lawyer and business, and that only $29 \%$ of girls compared to $51 \%$ of boys say engineering would be a good or very good profession for someone like them.

Six curriculum units based on four Grand Challenge themes have been developed and piloted at six Wisconsin public middle schools:

- Health Care: Biomedical Imaging

- Water Resources: Drinking Water Quality

- Improving Aging Infrastructure:

o Bridge Restoration

o Seismic Retrofitting

- Solar Energy:

o Solar Cookers

o Photovoltaics for Lighting

Each unit is structured to emphasize the following five elements of engineering practice: 1) iterative design process, refinement of design, 2) societal context, 3) application of math and science concepts, 4) collaborative activities, and 5) technological and non-technological design constraints. Instructional materials for each unit include detailed guides for both teachers and students, and employ realistic fictional scenarios to engage a broad spectrum of students through role play as engineers as they tackle hands-on design problems inspired by real societal needs. Standards-based middle school math and science content, selected to support unit activities, is integrated into the units, logically intertwined in a manner consistent with recommendations in the Next Generation Science Standards (NGSS) ${ }^{15}$. Each unit is designed to last 2-3 weeks, and each school selected a subset of three to four units to implement during the 2012-2013 academic year. The timing of the individual units during the school year was determined by each participating school team for optimal integration with their existing math and science curricula.

“Water Resources: Drinking Water Quality” is one example of an instructional unit. The unit incorporates a variety of pedagogical strategies to engage students in purposeful engineering, science and math activities to achieve short term goals within the fictional story line. Strategies are listed below, along with descriptions of how they are implemented in the unit.

- Role play: throughout the module, student groups role-play as a team of engineers and scientists (an environmental engineer, a chemical engineer, a geological engineer and a hydrologist) working in a consulting firm. The unit begins with a read-aloud dialogue, among team members as they return from a research conference on global water 
resources, that introduces social and scientific challenges associated with meeting this basic human need worldwide.

- Fictional story line with realistic elements: The consulting firm assigns the team to a contract it receives from a city in Yemen to evaluate a suspected problem with the local well water and to recommend a solution suited to the local environment. Suspected chemical and biological contaminants include nitrate, arsenic and E. coli.

- Teamwork: Each team of four splits up for training in their respective discipline. When the group subsequently reconvenes as a team, their success will depend on each member contributing based on their respective specialized training.

o Chemical engineers: representatives from each team gather for "testtube"experiments and data graphing to understand transport of chemicals from contamination sites to ground water sources.

o Environmental engineers: perform absorption measurements using visible light and use error analysis methods to "calibrate” instruments for later determination of the concentration of bacteria in ground water samples.

o Geological engineers: conduct in-class experiments to understand the entrainment of contaminants in flowing ground water.

o Hydrologists: evaluate the role of soil porosity in the transport of contaminants using a variety of sample types in controlled experiments in graduated cylinders.

- Board game: Teams use a map and their collective expertise to decide where to take water samples to determine the source of contamination. The decision will be based on preliminary data and their drilling budget. After each sample is drilled, the team receives a card with results from the selected site, in the form of raw data to be analyzed and used to inform subsequent rounds of drilling until the source of contamination is determined.

- Iterative design: Teams conduct experiments to evaluate feasibility of different methods of desalination as options for meeting the water needs of the community, considering cost, space, environmental impact, etc. Students propose modifications to improve desalination performance.

- Reporting: Students review contamination remediation options and must also consider an option to desalinate ocean water as an alternative. Teams create a treatment plan for the city, with recommendations based on the type of contaminants found, costs, local resources needed for long term management, local geography, etc. There is no single "right answer" to this challenge, and students are required to consider trade-offs and to prioritize in making their recommendation.

The instructional materials for each Grand Challenges unit includes a "teacher's guide" which has a table indicating the learning goals addressed by the student activities included in the unit. An example for the drinking water quality unit is shown in Table 1, with activity descriptions as follows:

1. “A Request for Help” - A city requests consulting assistance on a water contamination problem; role-playing teams are formed and review the problem. 
2. “Always More to Learn” - Each student in the team adopts a different engineering/science specialty and receives training in that specialty.

3. “Testing the Waters" - After reuniting, teams combine member expertise in specialty disciplines to devise a plan for where to take water samples to (via a board game) pinpoint the contamination source.

4. "A Salty Drink" - Teams consider the feasibility of a desalination plant to address future water needs and test desalination methods.

5. “A Satisfying Solution” - Teams consider benefits and costs of different water treatment options to resolve the contamination problem.

6. "Closing the Case" - Teams prepare a final report that summarizes their work and conclusions, and finishes up with a recommendation to the city.

Learning goals include science and math concepts and practices that align with state standards, as well as engineering design concepts and practices. Each activity has multiple goals, and most goals are listed under more than one activity. Each activity and goal is driven by the story line so that students experience their relevance in a realistic context.

Training for the middle school partners included two "summer institutes" at UW-Madison in 2011 and 2012, of four and three days duration, respectively. At the first summer institute, participants were given a detailed introduction to the "Grand Challenges for Engineering," including current research activities on campus relevant to the instructional modules, through presentations and lab tours. Most of both summer institutes, however, was devoted to testing of the instructional units in draft form. The school teams played the role of students as they worked through the instructional activities. This served the dual purposes of vetting the instructional modules and preparing the teachers for using the units in their own classroom. Both summer institutes also included planning time for the school teams, using an implementation framework introduced at the first summer institute. Each unit was revised extensively based on experiences and feedback at the summer institute, before delivery of the final version for classroom use.

\section{Purpose \& Research Questions}

This study examined students' self-reported social cognitive beliefs towards math and science to identify whether differences exist by membership in either the pilot curriculum or comparison group. Specifically, the following research questions were explored:

- Do students' self-efficacy scores in math and science differ as a function of treatment group membership?

o If so, do observed differences vary across schools?

- Do students' outcome expectation scores in math and science differ as a function of treatment group membership?

o If so, do observed differences vary across schools? 
Table 1: Matrix of Water Module Learning Goals and Student Activities

\begin{tabular}{|l|c|c|c|c|c|c|}
\hline & \multicolumn{5}{|c|}{ Activities } \\
\hline Goals & $\mathbf{1}$ & $\mathbf{2}$ & $\mathbf{3}$ & $\mathbf{4}$ & $\mathbf{5}$ & $\mathbf{6}$ \\
\hline $\begin{array}{l}\text { Identify some of the major issues } \\
\text { associated with the global fresh } \\
\text { water supply. }\end{array}$ & $\mathrm{X}$ & & $\mathrm{X}$ & & & \\
\hline $\begin{array}{l}\text { Understand fundamental } \\
\text { environmental, geological and } \\
\text { physical science concepts related } \\
\text { to water resources and the solving } \\
\text { of related problems. }\end{array}$ & & $\mathrm{X}$ & $\mathrm{X}$ & & & \\
\hline $\begin{array}{l}\text { Collect data and use that data to } \\
\text { create explanations. }\end{array}$ & & & $\mathrm{X}$ & $\mathrm{X}$ & & \\
\hline Design, create and test models & & & & $\mathrm{X}$ & & \\
\hline $\begin{array}{l}\text { Communicate scientific and } \\
\text { technical information effectively. }\end{array}$ & & & & & & $\mathrm{X}$ \\
\hline $\begin{array}{l}\text { Working within given constraints, } \\
\text { collaboratively define a problem, } \\
\text { design a plan for collecting data, } \\
\text { analyze the data, and propose and } \\
\text { optimize a design solution to } \\
\text { address the problem. }\end{array}$ & $\mathrm{X}$ & & $\mathrm{X}$ & $\mathrm{X}$ & $\mathrm{X}$ & \\
\hline $\begin{array}{l}\text { Understand the interdependence of } \\
\text { Science, Engineering, and } \\
\text { Technology and the way that they } \\
\text { influence societal and personal } \\
\text { options. }\end{array}$ & & $\mathrm{X}$ & $\mathrm{X}$ & $\mathrm{X}$ & $\mathrm{X}$ & $\mathrm{X}$ \\
\hline $\begin{array}{l}\text { Identify, investigate, and } \\
\text { experience the knowledge, skills } \\
\text { and dispositions required for work } \\
\text { as a professional engineer. }\end{array}$ & $\mathrm{X}$ & $\mathrm{X}$ & & & & \\
\hline $\begin{array}{l}\text { Use mathematics to determine and } \\
\text { describe the magnitude of a } \\
\text { resource management problem. }\end{array}$ & $\mathrm{X}$ & & $\mathrm{X}$ & & & \\
\hline $\begin{array}{l}\text { Analyze data, plot and calculate a } \\
\text { standard curve. }\end{array}$ & & $\mathrm{X}$ & & & & \\
\hline
\end{tabular}

\section{Methods}

Procedures \& Participants. Five middle schools (3 urban, 2 rural) in the upper-Midwest participated in this study. Training workshops were provided to familiarize teachers from participating schools with the modules, and to plan their implementation in math and science classes. Human subjects approval was obtained from both the researchers' university and the participating school districts before the commencement of data collection. Parental consent and 
student assent were also obtained. Student data was collected from two student groups (participating and non-participating students) prior to implementation in the fall of 2012. Postimplementation data was collected in late spring 2013. At both the pre-curriculum and postcurriculum time points, the students completed research measures by accessing a secure online survey hosting website. Both the pre- and post-surveys took approximately 40 minutes to complete.

Seven hundred twenty-eight (728) middle school students participated in this study. Four hundred sixty-three (463) students received the curriculum in the classroom, while the remaining 265 served as comparison youth. The number of youth participating by school can be found in Table 2, while a break down by gender, racial/ethnic background, and socioeconomic status (SES) can be found in Table 3. Please note, student SES was measured by identifying students who qualified for free or reduced-cost school lunches.

Table 2: Number of Participants by School \& Research Group

\begin{tabular}{l|c|c|c}
\hline & $\begin{array}{c}\text { Location of } \\
\text { School }\end{array}$ & $\begin{array}{c}\text { Received } \\
\text { Curriculum }\end{array}$ & Comparison Group \\
\hline School 1 & Rural & 78 & 89 \\
\hline School 2 & Rural & 70 & 51 \\
\hline School 3 & Urban & 63 & 42 \\
\hline School 4 & Urban & 176 & 36 \\
\hline School 5 & Urban & 76 & 47 \\
\hline Total & & $\mathbf{4 6 3}$ & $\mathbf{2 6 5}$ \\
\hline
\end{tabular}

Table 3: Number of Participants by Gender, Racial/Ethnic Group, Income Status, \& Group

\begin{tabular}{l|c|c}
\hline & $\begin{array}{c}\text { Received } \\
\text { Curriculum }\end{array}$ & $\begin{array}{c}\text { Comparison } \\
\text { Group }\end{array}$ \\
\hline Female & 228 & 135 \\
\hline Male & 235 & 130 \\
\hline White & 315 & 192 \\
\hline Hispanic/Latino & 72 & 30 \\
\hline African American & 64 & 29 \\
\hline Asian/Pacific Islander & 11 & 11 \\
\hline Native American & 0 & 1 \\
\hline Multi-racial or Other & 1 & 2 \\
\hline Low Income & 221 & 121 \\
\hline Not Low Income & 242 & 144 \\
\hline
\end{tabular}

Middle School Self-Efficacy Scale (MSSE). At present, no validated engineering efficacy/outcome expectation measures exist that are appropriate for use with middle schoolaged youth. Further, measures of social cognitive variables focus on individuals' beliefs about tasks within a domain (vs. global feelings about a domain); in middle school engineering tasks that youth would undertake require the application of math/science skills and concepts. Therefore, engineering efficacy and outcomes expectations may be adequately captured by assessing math/science self-efficacy and outcomes expectation beliefs. 
As part of a larger set of measures, student participants were asked to complete Middle School Self-Efficacy Scale (MSSE). The MSSE assesses student self-efficacy and outcome expectation beliefs in math and science ${ }^{3}$. Self-efficacy and outcome expectations in math and science were evaluated by four subscales respectively. The Math Self-Efficacy (MSE) and Science SelfEfficacy (SSE) subscales assess students' self-reported confidence to complete various math and science tasks, while the Math and Science Outcome Expectations, Intentions, and Goals (MOIEG and SOIEG) subscales assess students’ beliefs about outcomes associated with pursuing activities in math and science domains. On the self-efficacy scales, students use a 5point Likert scale ranging from Very High Ability to Very Low Ability to indicate the extent to which they believe they could achieve certain outcomes in math and science. Students also use a 5-point Likert scale to respond to items on the MOIEG and SOIEG subscales. On these subscales students indicate the extent to which they agree/disagree with statements about math and science. Sample items can be found in Table 4.

Table 4: MSSE Sample Items by Subscale

\begin{tabular}{l|l|l}
\hline Subscale Domain & Sample Item - Math & Sample Item - Science \\
\hline Self-Efficacy & $\begin{array}{l}\text { Determine the amount of sales } \\
\text { tax on clothes I want to buy }\end{array}$ & $\begin{array}{l}\text { Predict the weather from } \\
\text { weather maps }\end{array}$ \\
\hline Outcome Expectations & $\begin{array}{l}\text { If I take a lot of math courses, } \\
\text { then I will be better able to } \\
\text { achieve my future goals }\end{array}$ & $\begin{array}{l}\text { If I do well in science, then I } \\
\text { will be better prepared to go to } \\
\text { college }\end{array}$ \\
\hline
\end{tabular}

\section{Results}

A pre/post, comparison group design was used to examine student data. Group differences were assessed using Analysis of Covariance (ANCOVA). Pre-test scores served as covariates. As this was the initial efficacy examination of the engineering-based curriculum described above, a more liberal p-value of 0.10 was considered, but only when the accompanying effect size measure (i.e., $\eta^{2}$ ) reached a meaningful level. In the social and educational sciences, $\eta^{2}$ values of 0.01 indicate a small, but meaningful effect, while $\eta^{2}$ of 0.06 to 0.13 are indications of medium and large effects, respectively.

Results indicate that in three of the five participating schools, youth who experienced the curriculum modules in the classroom reported significantly higher social cognitive beliefs than the comparison group (see Table 5). Specifically, higher math efficacy scores were found for target youth in one school and higher science efficacy scores were also found for target youth in one school, indicating that at post-test, youth in these schools who had experienced the modules reported more confidence for engaging in math- and science-related tasks, respectively.

At the same time, higher math outcome expectations were found for target youth in three schools. Further, higher science outcomes expectations were found at one school. Thus, youth in these schools who had experienced the pilot curriculum in the classroom reported more positive beliefs about the outcomes associated with studying math and science and about their intentions and goals around future math and science pursuit. 


\begin{tabular}{c|l|l|l}
\hline & $\boldsymbol{F}$ (degrees of freedom) & $\boldsymbol{p}$-value & $\boldsymbol{\eta}^{2}$ \\
\hline Math Self-Efficacy & & & \\
\hline School 5 & $F(1,99)=4.036$ & $<0.005$ & 0.04 \\
\hline Science Self-Efficacy & & & \\
\hline School 5 & $F(1,103)=7.012$ & $<0.01$ & 0.065 \\
\hline Math Outcome Expectations & & & \\
\hline School 1 & $F(1,144)=2.807$ & $<0.10$ & 0.019 \\
\hline School 4 & $F(1,196)=2.805$ & $<0.10$ & 0.014 \\
\hline School 5 & $F(1,101)=4.513$ & $<0.05$ & 0.044 \\
\hline Science Outcome Expectations & & & \\
\hline School 1 & $F(1,136)=5.614$ & $<0.05$ & 0.04 \\
\hline
\end{tabular}

\section{Discussion \& Implications}

This study examined middle school students' self-reported social cognitive beliefs towards math and science as a function of participation in an engineering-based curriculum infused into math and science classes. Modest, though important results were found. These results have implications for future research and, if replicated, for pre-college engineering education initiatives.

Math/Science Domain: Social cognitive beliefs differed in meaningful ways across six separate analyses. In four of these six instances, after controlling for pre-test scores, students who received the pilot curriculum demonstrated more positive beliefs about math at post-test than the comparison group, while two of the six significant results involved science-related beliefs. It is important to note that the schools in this study were able to determine where [i.e., in which class(es)] to implement the curriculum. One hypothesis that could be made is that students' beliefs will be more impacted by the curriculum when it is experienced in a particular course (i.e., math beliefs when experienced in a math course). This, however, was not the case in the present study. Upon further inspection we found that our students were just as likely, if not more likely, to experience the curriculum in science classes as in math classes. Of the four significant, positive effects we found for math-related social cognitions, only one occurred in a school that infused the curriculum into math courses only. The other significant effects occurred in schools that infused the curriculum into both math and science courses.

A more plausible explanation may be found in the nature of the curriculum and the learning tasks themselves. The curriculum assessed here uses realistic, though fictional, scenarios to provide a context for the challenges presented and the decisions and actions required to create a solution. Such context-rich and collaborative instruction may be more consistent with the experiences students have previously had in science classes versus math classes. If so, the context-driven nature of engineering problems may support the development of math confidence and beliefs about math-related outcomes and goals particularly well. Further investigation is warranted as such a result, if replicated, could have important implications for educational practice.

Social Cognitive Beliefs: While the results of this study found significant results across both types of social cognitive beliefs, students' beliefs about outcomes and their future pursuits in 
math and science were more likely to be influenced than those about self-efficacy. While further research will be needed in order to determine whether this is a consistent finding and the reason for the finding, one hypothesis may be found in Bandura's 5 , "sources" of social cognitive beliefs. According to his theory, self-efficacy and outcome beliefs are shaped through past performance accomplishments, vicarious learning opportunities, verbal feedback/persuasion by influential others, and the ability to manage the emotional arousal associated with new learning experiences. Given that the pilot curriculum experienced by the youth was time-limited, it is unlikely that all sources of social cognitive beliefs were equally present. Past performance accomplishments, for example, require multiple opportunities to experience success within a particular domain of tasks and accumulate over time. They can, however, be particularly influential for the development of confidence.

At the same time, beliefs about the positive outcomes associated with pursuing and succeeding in math and science studies may be more amenable to intervention than efficacy beliefs. Both types of beliefs are important to encourage. Thus, it may be useful for future engineering education initiatives to intentionally incorporate multiple opportunities for youth to experience the range of Bandura's sources of social cognitive beliefs, with the purpose of supporting youths' selfconfidence and beliefs about future endeavors in math and science, particularly in the context of engineering challenges.

Geographical setting: Five schools participated in this study: two located in rural areas and three in urban school districts. No location-based differences in results or pattern of results were found. While no location-specific hypotheses were offered it is important to note that students in both urban and rural schools were just as likely to report differences in social cognitive beliefs about math and science. This is interesting as it is often assumed that youth in urban areas have more access to both formal and informal education and exposure opportunities in STEM fields, generally, and engineering fields, specifically. Urban youth live in closer proximity to a range of different STEM and engineering-related industries and extracurricular informal education venues, such as museums of science and natural history. For this reason it is often assumed that youth in rural areas will be more impacted by curricula designed to immerse them in STEMoriented activities.

At the same time it is important to recognize that Midwestern urban schools often have larger populations of youth of color than do rural schools. Existing research has shown that students of color enter post-secondary engineering education at lower rates than their majority peers. While not part of this study, future research may examine differences in the impact of engineering educational activities by racial/ethnic group as well as potential interaction effects with location of school. The results of such studies could contribute to our knowledge regarding how to encourage broader participation in post-secondary engineering education by under-represented groups of students.

\section{Conclusion}

In sum, the engineering-based curriculum described here and piloted in middle schools in Wisconsin shows promise in its ability to shape students' attitudes towards math and science. When compared with youth who did not experience the Grand Challenges for Engineeringinspired curriculum, students in target classrooms reported more positive social cognitive beliefs 
towards math and science in six instances. Beliefs about outcomes and future goals associated with studying math appeared particularly impacted by the context-rich, collaborative engineering-based curriculum.

\section{References}

1 Fouad, N. A. (1995). Career linking: An intervention to promote math/science career awareness. Journal of Counseling and Development, 73, 527-534.

2 Brown, S. \& Lent, R. (2005.) Career development and counseling: Putting theory and research to work. Hoboken: John Wiley \& Sons.

3 Fouad, N.A., Smith, P.L., \& Enochs, L. (1997). Reliability and validity evidence for the Middle School SelfEfficacy Scale. Measurement and Evaluation in Counseling and Development, 30, 17-31.

4 Katehi, L., Pearson, G., \& Feder, M. (Eds.) (2009). Engineering in K-12 education: Understanding the status and improving the prospects. Washington, DC: National Academies Press.

5 Bandura, A. (1986). Social foundations of thought and action: A social cognitive theory. Englewood Cliffs, NJ: Prentice Hall.

6 Bandura, A. (1997). Self-efficacy: The exercise of control. New York: Freeman.

7 Betz, N. E., \& Hackett, G. (1981). The relationship of career-related self-efficacy expectations to perceived career options in college women and men. Journal of Counseling Psychology, 28, 399-410.

8 Lent, R. W., Brown, S. D., \& Hackett, G. (1994). Toward a unifying social cognitive theory of career and academic interest, choice, and performance [Monograph]. Journal of Vocational Behavior, 45, 79-122.

9 Lent, R. W., Brown, S. D., \& Larkin, K. C. (1986). Self-efficacy in the prediction of academic performance and perceived career options. Journal of Counseling Psychology, 33, 265-269.

10 Fouad, N. A., \& Smith, P. L. (1996). A test of a social cognitive model for middle school students: Math and science. Journal of Counseling Psychology, 43, 338-346.

11 Plant, E.A., Baylor, A.L., Doerr, C.E., \& Rosenberg-Kima, R.B. (2009). Changing middle-school students' attitudes and performance regarding engineering with computer-based social models. Computers and Education, 53, 209-215.

$12 \mathrm{Mau}, \mathrm{W}-\mathrm{C}$. (2003). Factors that influence persistence in science and engineering career aspirations. Career Development Quarterly, 51, 234-243.

13 National Academy of Engineering. (2008). Grand Challenges for Engineering. Available: http://www.engineeringchallenges.org/. [Accessed April 9, 2012].

14 National Academy of Engineering. (2005). Extraordinary Women Engineers: Final Report. Available: http://wie.engineering.ucdavis.edu/pages/EWEPFinal.pdf. [Accessed December 20, 2013].

15 National Research Council. (2013). Next Generation Science Standards: For States, By States. Washington, DC: The National Academies Press. 


\section{Acknowledgements}

The research described here was funded in part by the National Science Foundation (award DRL - 1020126), the Plexus Foundation, and the Young Scientists of America. 